\title{
Study on the Application Design of Hubei Folk Brocade Patterns
}

\author{
Lin Liu \\ School of Art and Design \\ Hubei University of Technology \\ Wuhan, China
}

\author{
Qinqin Xiao \\ School of Art and Design \\ Hubei University of Technology \\ Wuhan, China \\ 987628111@qq.com
}

\begin{abstract}
In this article, the design aims to merge a large amount of information into an easy-to-understand art form through the image-text combination and hand-drawn form to enable more people to better know Hubei brocade, thereby excavating the historical and realistic value existed all time throughout the ages down the ages and better building up a good image among the masses. The work combed a large amount of historical information, which thereafter was converted into several pieces of graphically and digitally clear image-text combination information. Centering on the concept of highlyefficient popularization of folk culture and considering the effectiveness of information content dissemination, there were new concept designs carried out from such aspects as font and image, for achieving the purpose of a highly-efficient popularization of the knowledge and culture of the non-material cultural heritage of brocade.
\end{abstract}

Keywords-Hubei; folk embroidery; information visualization; graphic design

\section{INTRODUCTION}

\section{A. Research Background}

China has developed rapidly and entered a new era, thriving and strong. The non-material cultural heritage passed down from generation to generation however is in the midst of a decline. The rescue and protection of non-material cultural heritage is also an indispensable part of Chinese culture rejuvenation, building the Chinese dream and enhancing cultural self-confidence. In this paper, combined with the practical application research of visual communication design, it analyzed and integrated the three famous Hubei brocade patterns. Meanwhile, there were new innovations carried out by hand-drawing that the patterns are drawn in the font graphics. The design was demonstrated in a practical process, which includes the multi-aspect visualization presentation and the modification and refining process combing with the thoughts of hand-drawn presentation of patterns in font graphics. [1] In the era of informationized business, people will naturally generate new aesthetic standards and trends, which at the same time determines that the culture of folk craftsmanship needs the overall brand image promotion strategy to play a good "cultural card", so that we can continuously enhance the charm and attraction of Hubei Region, correctly master the law of cultural development and effectively enhance the cultural consciousness and cultural self-confidence.

\section{B. Domestic status and dilemma}

One of the cultural symbols and labels of Hubei people is the rich Jingchu folk brocades. However, due to historical reasons and the limitations of manual inheritance, there have been increasingly prominent problems for the handicraft of Jingchu brocades in the process of going towards the market. At the end of the 20th century, the rapid development of the Internet and computer science almost covered the whole growth period of The Millennials. Difficult it was to balance the merging and collision between Chinese and Western cultures, and the adverse phenomenon such as the lack of interest in folk crafts has rendered the brocade art culture to go downhill. [2]

\section{Research content}

To provide a good theoretical basis and factual basis for the application design of the pattern, the relevant documents of Hubei brocade crafts and the craftsmanship were studied to attain an in-depth understanding of the value and culture of the brocade crafts.

(1) Knowing the Hubei folk brocade. The spotinvestigation of the Jingzhou Museum, the Hubei Provincial Museum, the Wuhan Museum, the Hankouli Crafts Shops, the Yangtze River Museum of Non-Material Cultural Heritage, the Changyang Tujia Autonomous County Museum, and the Han Embroidery Base of the Tanhualin Art Village was carried out.

(2) Application Design Practice Report of Brocade Pattern. Practice Report on the Application Design of Brocade Pattern. Taking Xilan Kapu, Han Embroidery, and Huangmei Peach-blossom Embroidery as the examples, the presentation of image-text combined information was carried out from various aspects such as required tools, basic needling, pattern theme, modeling method, image-composition method and fabrication process. Meanwhile, the font pattern suitable for popularization and decoration was hand-sketched by using the acrylic paint. 


\section{UNDERSTANDING THE HUBEI FOLK BROCADE}

\section{A. Understanding the brocade}

As the woven fabric invented by the people of Hubei in the daily life process, Hubei Brocade plays a very important role in folk activities such as livelihood, sacrifice, costumes and decoration. In the past, these woven fabrics were daily necessities of ordinary people, but under development in the long history, with the constant improvement, development and artistic creation they have been given very profound regional color and emotional meaning. (See Fig. 1)

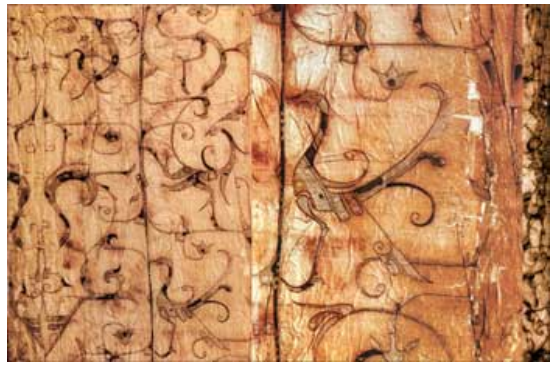

Fig. 1. Red-brown silk embroidered phoenix flower pattern-Collection in Hubei Jingzhou Museum

\section{B. Analysis of Category, Color and Graphics of Brocade}

The main study objects are Xilan Kapu, Han Embroidery and Huangmei Peach-blossom Embroidery. Most of the patterns of Tujia Xilan Kapu brocades are the geometric figures consisted by specific graphics drawn by horizontal lines and vertical lines. It becomes a new shape through the coincidence of graphics, or the borrowing and copy between graphics. [3] The color is more focused on the contrast and comparison, with the red and black becoming the peoplefavored color and the yellow, blue and white as the embellishment. There is no absolute figurativeness pattern in the Huangmei peach-blossom pattern, which majorly emphasizes the presentation of artistic spirit and philosophy and extensionally draws an ideal world, which mostly is to express a symbolic meaning. Generally, red and pink are primary tones, and the black and the dark blue are used as the background color. Influenced by Jingchu folk culture, the pattern of Han embroidery, which mostly stresses the auspiciousness, not only depicts the common animals and plants but also portrays the virtual auspicious beast and propitious cloud. And it's characterized by the "glorious color" featuring by the "gold-and-silver embellished embroidery with five major colors stratified and set each other off"-that is similar to the tradition of Chu culture, with red, yellow, blue, white and black as the preferred choice and occasionally with gold and silver, but the overall color saturation is a little more.

\section{REPORT ON DESIGN PRACTICE}

\section{A. Upfront investigation and document preparation and sorting}

Here, an analysis of various kinds of brocades in Hubei Province was completed, which would provide a certain theoretical basis and evidence for the later design. In the process, it emphasized the study and interpretation of Xilan Kapu, Huangmei Peach-blossom Embroidery, and Han embroidery. Not only was the status quo of brocade techniques understood, but the graphic patterns were sorted in terms of various aspects, with summarization and categorization. Also, it drew in the merits of the patterns and solved the issues that may happen in the modern visual popularization.

The spot investigation was conducted in Wuhan, Jingzhou, Yichang and other places, and then the local cultural spirit of Jingchu was summarized. During the view in the Hubei Provincial Museum, the Hankouli Crafts Shops and the Yangtze River Museum of Non-material Cultural Heritage, it had put great efforts to make an in-depth learning for the Han embroidery, which on the one hand was intending to find the prominently advantageous aspect of the Chinese embroidery in the excavated Chu embroidery heritages, and on the other hand was to photograph a large number of modern Han embroidery handicrafts in the museum for a further design; and a large number of brocade patterns in the Jingzhou Museum was collected; the real Xilan Kapubu bags and hangings and other antiques were found in the Changyang Tujia Autonomous County Museum and Qingjiang Gallery Crafts Sales Zone, providing several series of patterns for the establishment of the design data repository.

\section{B. Conception and sketch of the presentation form}

By using the Visualization presentation form to integrate the base data of Hubei folk brocade techniques, it planned to extract and comb abundant font information and utilize the definition, attribute characteristics of each technique to carry out an excellent categorization, thus providing a kind of useful, and easy-to-learn material. After summarizing and combing all kinds of categories, the information relationship in the view to be showed in front of the reader's eyes can be strengthened by presenting graphics, typesetting and sample patterns, therefore the data can be more clearly interpreted and remembered by the viewer. [4] Visually guiding people to smooth their understanding of traditional culture and quickly understand the information that designers have presented would have a positive effect on improving the influence of Hubei Jingchu folk brocade handicrafts in the market. Furthermore, in order to deepen the viewer's impression of Hubei brocade, the patterns of Xilankapu, Han Embroidery and Huangmei Peachblossom Embroidery were decomposed and reconstructed, and then the sketch was drawn through the hand-painted form by using the acrylic paint. [5]

\section{Presentation of visualization design for the combed knowledge and information of brocade}

In this section, all kinds of Hubei brocade were categorized, and the distribution area was shown, with the major area distinguished. The visualization presentation design for the geographic distribution information of Hubei folk brocade categories was displayed; also, the graphic patterns of Huangmei Peach-blossom Embroidery, Han Embroidery and Xilankapu were collected, and then the material patterns were 
selected, sorted and categorized for further visualization design. [6]

Hand-drawn illustration font design

Through the study and research on the three patterns of Xilan Kapu, Huangmei Peach-blossom Embroidery and Han Embroidery, the patterns were deconstructed and reorganized by hand-painted forms by using the acrylic paint, which was expected to facilitate the viewer's speed of perception, acceptance and agreeable sense of the folk non-material cultural heritage of Hubei Brocade. (See Fig. 2). The internal patterns of the words "湖" and " $\square$ " are mainly derived from the dragon pattern, the phoenix pattern, the Buddha's-hand pattern and the peony pattern of Han embroidery; the internal pattern of the "北" word is mainly derived from the "Maogusi" and the figure of "The Marriage of the Mouse's Daughter" of Xilan Kapu; the internal pattern of the " $\square$ " word mainly comes from the patterns in the kerchief and apron that have the Huangmei Peach-blossom pattern. Those extracted pattern elements were re-designed and combined to form a new pattern combination, and the integrated design practice was accomplished, with the best to achieve the effect of full and bright and form a strong contrast.

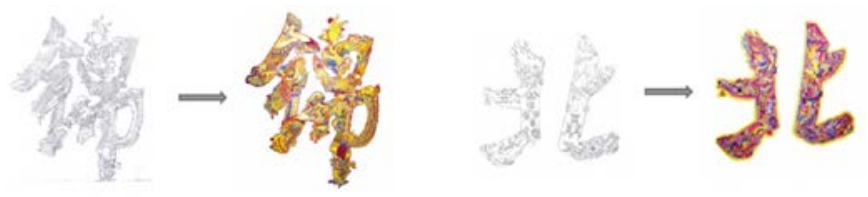

Fig. 2. Illustration of acrylic-paint hand-painted pattern

\section{Propaganda Poster with Pattern-element}

The series of posters (as shown in Fig. 3) begins with the abstract graphics and seeks the graphic patterns in the brocade crafts itself, which captures the image and aesthetic spirit of the brocade culture and conveys it to the audience by means of graphic layout rather than text, so as to more effectively meet the memory and aesthetic needs of the audience. By overall enhancement on the style of the propaganda design of the nonmaterial heritage of brocade culture and the efficient dissemination of the regional brand value, it will better spread the hope of exquisite life of Hubei people to the people of all ethnic groups.

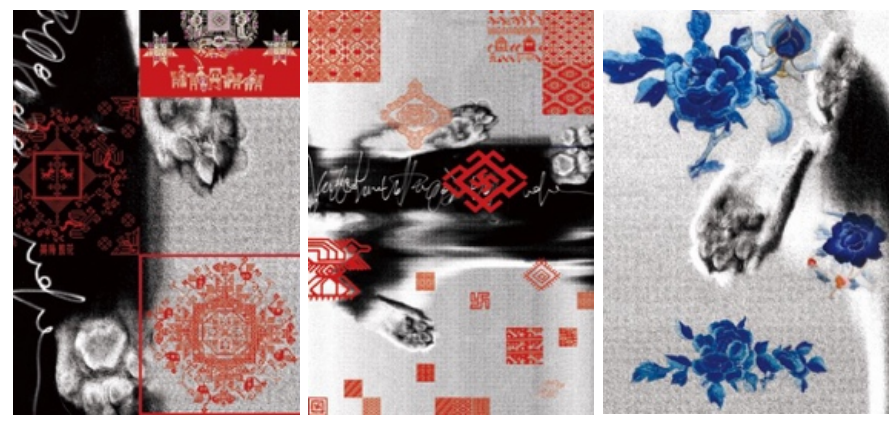

Fig. 3. Three brocade poster designs

\section{REFLECTIONS ON THE PROTECTION OF NON-MATERIAL Cultural Heritage of Brocade AND MOdERn Brocade DESIGN}

\section{A. Relationship between brocade culture protection and modern design}

Through the investigations, it's found that the existing brocade culture of the Hubei non-material cultural heritage had insufficient propaganda for its protection and inheritance, and there were fewer good designs in the process. The folk brocade culture was supposed to be spread along with the dissemination of local Jingchu culture. However, in the design and popularization process, the cultural connotation and legendary story contained in it were often ignored. Upon the investigation conducted in the Jingzhou Museum, the Hankouli Handicrafts Shops in Wuhan and the Yangtze River Museum of Non-material Culture Heritage, considering the commonweal publicity and popularization of the existed Nonmaterial Culture Heritage, it discovered that most of the current basic researches on the folk brocade are text-type information, lacking the certain degree of integration and linking of the market-oriented aesthetic trends and cultural creativity-which are helpful for the popularization and the construction of an overall brand culture. Concretely, the refinement of cultural concepts was somewhat simple, the patterns were not exquisite enough, the design creativity lacked personality, and the publicity and distribution had not yet met the aesthetic needs. To some extent, the defects in those aspects also affected the consumers' willingness to learn and inherit.

In the modern informationized business era, people will naturally generate new aesthetic standards and trends. The inheritance of the brocade culture cannot put aside the important process of the art design. To salvage and inherit the non-material cultural heritage, the key thing is to do a good job in the popularization and the aesthetic design thereinto. In the current stage, the commonweal publicity video and the posters just only spread all over the streets literally in names, and there is no guiding significance for the research on the aesthetic concept and audiences' psychology and experience. For an the instant, many propaganda promotions for the Nonmaterial cultural heritage fail to quickly deliver their characteristics to the audiences' eyes in a clear and terse manner, especially in a place where it could draw many audiences' attention. In this regard, the work was carried out the research, design and practice on the application of brocade patterns in font graphics, for the sake of strengthening the popularization and promotion effect of Hubei folk brocade technique in our society.

\section{B. A new direction for the protection of the brocade technique in the salvaging of non-material cultural heritage}

Protecting cultural heritage is protecting the memory of people in a region. In the new era, the traditional techniques are urgently needed the intervention of new media, new ideas, and new means. If we want to drive young people to have more understanding of the brocade culture and inherit the brocade technique, there should be a new direction. In other words, only progress and development will lead to more 
abundant possibilities. It should adopt flexible applications of digital design methods to make an extensive publicity of the brocade culture and provide new means and technical support for the protection and development of cultural heritage. Through this investigation and research on the Hubei traditional brocade, the modeling language of the pattern and the special needling method-which are different from other techniques-are analyzed. [7] And it mainly implemented the visualization design for the information from the pattern, the fabrication process, the theme features, the modeling characteristics and the symbolic meaning, then transformed the abstract and complicated information into a clearer propaganda method for viewers. Furthermore, the design has given full consideration for the perspective of a viewer, and it has elaborated the categorization and the example illustration by using the graphic information or image-text information which were converted from the various document files and texts such as data statistics, pattern combing, historical traceability, geographic distribution, and relationship analysis. Therefore, a clear, logical and detailed presentation of the cultural heritage was formed in the paper. [8]

\section{CONCLUSION}

The core concept of this brocade application design is the "highly-efficient popularization". Entering the 21st century, along with fast-pace development, the traditional culture is increasingly impacted by the network culture and foreign culture. The development of folk brocade is stagnant or even goes downhill. Cultural self-awareness and cultural selfconfidence are not only an attitude but should be fulfilled with concrete behaviors and be inherited and evolved effectively. [9]The purpose of this design is to integrate a large amount of information into a more easy-to-understand art form through the combination of pictures and texts with hand painting, therefore the mass can better understand the Hubei Brocade, protect the brocade culture and discover its historical and realistic value in all ages from ancient to present. Then, it'll make us fast and elaborately set up a good cultural image in the masses, making a profound traditional culture become better and better in our life. [10] Especially, with the understanding of the historical process, the categorization of the patterns and the basic needling method description, the paper has successfully combed a large number of historical information into several image-text information, which is logically clear and graphically vivid.

\section{REFERENCES}

[1] Wu Chengguo. Blue Book of Hubei Culture [M]. Social Sciences Academic Press, 2016.

[2] Chen Shaohui, Deng Dandan, Chen Wenhua. Jingchu Folk Crafts [M] Wuhan University Press, 2014

[3] Wang Zhuomin. New Design for Folk Art: Digital Design for Xilankapu Pattern [M]. Hunan Normal University Publishing, 2014.

[4] Feng Zemin. Jingchu Han embroidery [M]. Wuhan Publishing House, 2012

[5] Yang Hong. Graphical Power: Information Visualization Design Method and Case Analysis [M]. Mechanical Industry Press, 2015

[6] Chen Gaoya. A Picture is Worth a Thousand Words: A Guide to the Information Visualization of Art Design [M]. Mechanical Industry Press, 2015

[7] (Qing) Ding Pei. Embroidery Book [M]. Zhonghua Book Company, 2012

[8] Li Xin. Digital Protection: A New Direction for the Protection of NonMaterial Cultural Heritage [M]. Science Press, 2011.

[9] He Chen. Chinese Female Red [M]. Gu Wu Xuan Press, 2009

[10] Zuo Shanghong. Jingchu National Non-material Cultural Heritage [M]. Hubei People's Publishing House, 2008 